JAMP: Jurnal Adminitrasi dan Manajemen Pendidikan

Volume 4 Nomor 2 Juni 2021, Hal : 163 - 170

Tersedia Online di http://journal2.um.ac.id/index.php/jamp/

ISSN 2615-8574 (online)

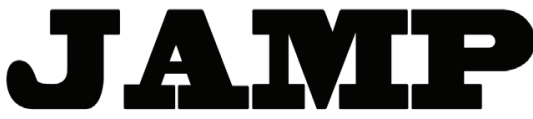

JURNAL ADMINISTRASI DAN MANAJEMEN PENDIDIKAN

\title{
ANALISIS SITASI PADA JAMP: JURNAL ADMINISTRASI DAN MANAJEMEN PENDIDIKAN, UNIVERSITAS NEGERI MALANG, 2018- 2020
}

\author{
Imam Gunawan \\ Jurusan Administrasi Pendidikan, Fakultas Ilmu Pendidikan, Universitas Negeri Malang, Indonesia \\ Email: imam.gunawan.fip@um.ac.id
}

\begin{abstract}
The level or number of citations for a journal and/or article is the main indicator for measuring the quality of a publication (paper). The purpose of this research is to determine the distribution of citations in JAMP: Journal of Educational Administration and Management. This research is included in research or studies on bibliometric analysis. The data source for this study is meta-data obtained from the JAMP: Jurnal Administrasi dan Manajemen Pendidikan, data citation download at Google Scholar, using the Publish or Perish 7 software, over a period of 3 years (2018-2020). Meta-data with the PoPCites.ris file format, processed with Publish or Perish 7 software, produces a description of the journal citation. The data is extracted into Microsoft Excel file format. The results of the analysis show that this journal has a citation level of 388. This article presents the 10 articles with the most citations. In addition, it also discusses topic trends in this journal in the last 3 years, as well as predictions of future article trends.
\end{abstract}

Keywords: citation analysis; education management; educational leadership; education supervision; publish or perish.

\begin{abstract}
Abstrak: Tingkat atau jumlah sitasi suatu jurnal dan/atau artikel merupakan indikator utama untuk mengukur kualitas suatu terbitan (paper). Tujuan riset ini adalah untuk mengetahui sebaran sitasi pada JAMP: Jurnal Administrasi dan Manajemen Pendidikan. Riset ini termasuk dalam riset atau studi tentang bibliometric analysis. Sumber data studi ini adalah meta-data yang diperoleh dari unduhan data sitasi JAMP: Jurnal Administrasi dan Manajemen Pendidikan di Google Scholar, dengan menggunakan software Publish or Perish 7, dalam kurun waktu 3 tahun (2018-2020). Meta-data dengan format file PoPCites.ris, diproses dengan dengan software Publish or Perish 7, menghasilkan sebuah hasil deskripsi tentang sitasi jurnal. Data tersebut diekstrak ke dalam format file Microsoft Excel. Hasil analisis diketahui bahwa jurnal ini memiliki tingkat sitasi sebanyak 388. Artikel ini menyajikan 10 artikel terbanyak sitasinya. Selain itu, juga dikupas tren topik di jurnal ini dalam kurun 3 tahun terakhir, serta prediksi tren artikel pada masa mendatang.
\end{abstract}

Kata kunci: analisis sitasi; manajemen pendidikan; kepemimpinan pendidikan; supervisi pendidikan; publish or perish.

Salah satu ukuran utama yang digunakan untuk menilai mutu suatu jurnal ilmiah adalah jumlah sitasi jurnal tersebut. Sitasi merupakan kegiatan merujuk artikel lain yang telah terbit (printed) atau sedang proses terbit (in press) dalam rangka untuk mendukung hasil riset yang dituangkan dalam bentuk artikel. Seorang penulis lazim melakukan pengutipan suatu karya ilmiah lain dengan berpedoman kaidah obyektif, saling menghormati, dan jujur. Oleh sebab itu, suatu jurnal perlu dianalisis secara periodik terkait dengan jumlah sitasi yang diperolehnya dari waktu ke waktu. Analisis ini digunakan untuk mengetahui perkembangan dan pertumbuhan jurnal ilmiah dalam kancah pengembangan bidang keilmuan yang menjadi ruang lingkup jurnal tersebut (Aljuaid, dkk., 2021). 
JAMP: Jurnal Administrasi dan Manajemen Pendidikan merupakan jurnal ilmiah yang diterbitkan oleh Jurusan Administrasi Pendidikan Fakultas Ilmu Pendidikan Universitas Negeri Malang sampai saat ini telah menerbitkan artikel dengan kurun waktu 3 tahun $(2018$ - 2020) dan telah terindeks Sinta 3. Jurnal ini fokus pada studi tentang manajemen pendidikan, kepemimpinan pendidikan dan supervisi pendidikan. Ketiga bidang keilmuan tersebut merupakan cabang dari studi tentang administrasi pendidikan (Gunawan \& Benty, 2017; Gunawan, 2019). Jika sekolah ingin sukses mencapai visi dan misinya, maka sekolah harus mengimplementasikan administrasi pendidikan yang baik (Kusumaningrum, dkk., 2019b; Wardani, dkk., 2020a; Taftania, dkk., 2020).

Seperti yang diuraikan pada paragraf pertama, untuk mengetahui kualitas jurnal ilmiah, salah satu cara yang dapat dilakukan adalah dengan menganalisis tingkat sitasi pada jurnal tersebut. Dengan menganalisis tingkat sitasi suatu jurnal, akan diketahui sebuah metrik jumlah artikel, jumlah sitasi jurnal, jumlah sitasi setiap artikel, dan ukuran indeksasi (misalnya h-index, g-index). Ukuran-ukuran tersebut juga lazim dijadikan bahan pertimbangan oleh penulis sebelum mengirim artikelnya ke suatu jurnal ilmiah, sebab hal ini terkait dengan reputasi jurnal maupun reputasi dari penulis itu sendiri. Jika suatu jurnal memiliki jumlah sitasi yang tinggi, maka dapat dikatakan bahwa jurnal tersebut memiliki dampak yang tinggi pula terhadap keilmuan. Dan hal ini juga berlaku bagi seorang penulis, jika penulis memiliki tingkat sitasi yang tinggi, maka ia dapat dikatakan memiliki dampak signifikan terhadap keilmuannya. Semakin besar jumlah sitasi, semakin besar pula kemanfaatan jurnal dan artikel tersebut.

Selain itu, dengan analisis sitasi, dapat diketahui topi kapa yang saat ini (on going) menjadi tren dalam suatu jurnal. Ukuran tren ini dilihat dari top artikel yang memiliki sitasi terbanyak di jurnal pada kurun waktu tertentu. Semakin banyak suatu artikel disitasi dan memuncaki top artikel terbanyak sitasinya, artinya tema artikel tersebut banyak dirujuk oleh artikel lain yang sedang menjadi trending topik, atau setidaknya artikel tersebut memiliki kekuatan keterkaitan (link strength) yang besar dengan artikel lain. Artikel ini menyajikan hasil analisis sitasi pada JAMP: Jurnal Administrasi dan Manajemen Pendidikan.

\section{METODE}

Metode riset ini termasuk dalam lingkup penelitian bibliometric analysis yang bertujuan untuk mengetahui sebaran sitasi pada suatu dokumen (paper, artikel, atau jurnal). Sumber data dari penelitian ini adalah meta-data JAMP: Jurnal Administrasi dan Manajemen Pendidikan yang diunduh dengan bantuan software Publish or Perish 7, pada kurun waktu 3 tahun, antara 2018 sampai dengan 2020. Meta-data ini disimpan dalam format file PoPCites.ris. Untuk keperluan proses deskripsi data, metadata tersebut selanjutnya diekstrak ke dalam file Microsoft Excel. Isi meta-data tersebut adalah nama penulis, tahun terbit, judul artikel, jumlah total sitasi, jumlah sitasi setiap tahun, dan URL artikel. Metadata tersebut diunduh pada tanggal 29 April 2021, alamat URL jurnal adalah http://journal2.um.ac.id/ index.php/jamp/index, e-ISSN 2615-8574. Gambar 1 menyajikan hasil unduh meta-data.

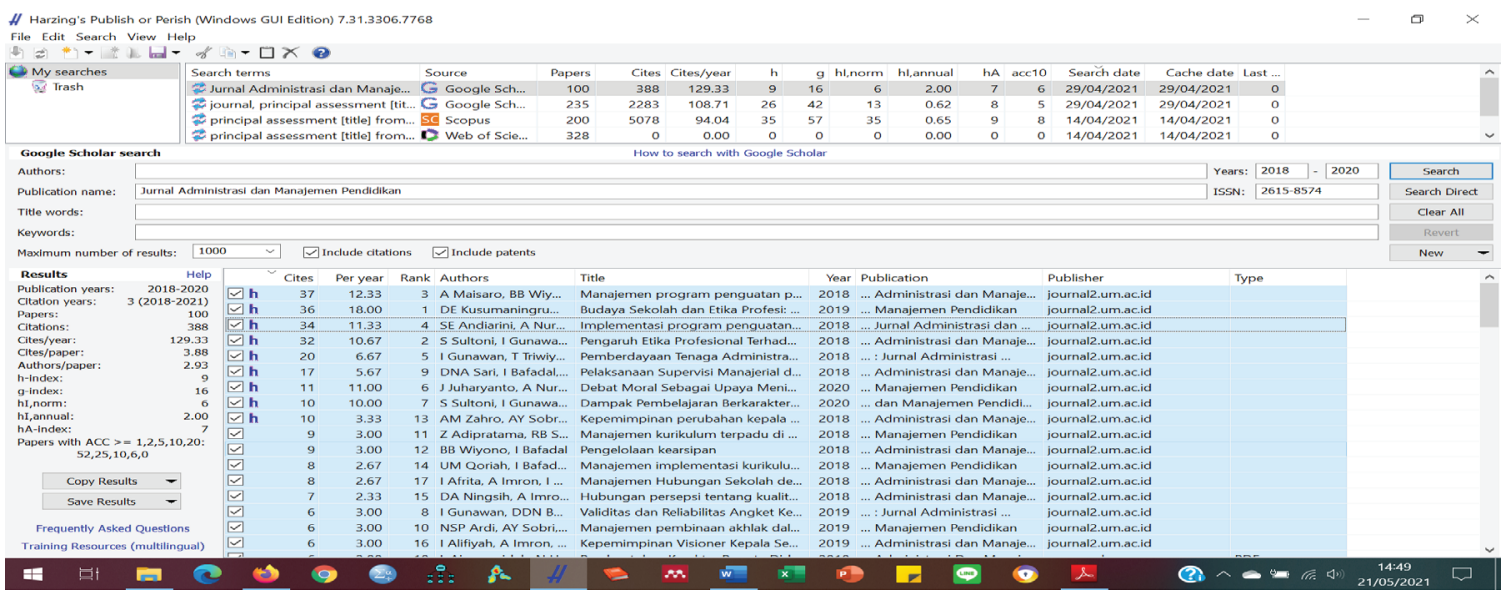

Gambar 1 Meta-data PoPCites.ris JAMP: Jurnal Administrasi dan Manajemen Pendidikan 
Proses unduh data ini tersinkronisasi dengan data akun Google Scholar yang dimiliki oleh JAMP: Jurnal Administrasi dan Manajemen Pendidikan, dengan URL https://scholar.google.co.id/citations? use $r=F P X 1 z s o A A A A J \& h l=i d$. Artinya Google Scholar dalam riset ini merupakan sumber meta-data berupa teks yang diunduh dengan software Publish or Perish 7. Karena meta-data yang dimiliki Google Scholar mencakup nama penulis, judul artikel, tahun terbit, jumlah sitasi artikel atau jurnal, dan menyediakan URL yang mengarah pada sumber website asli sebuah artikel, maka meta-data yang diunduh dengan Publish or Perish 7 pun juga memuat data tersebut.

\section{HASIL}

Indikator utama suatu jurnal ilmiah disebut bermutu adalah memiliki kontribusi bagi pengembangan dan kemajuan ilmu pengetahuan. Hal ini dapat diukur dari kontribusi artikel yang telah diterbitkan pada suatu jurnal untuk kemajuan ilmu pengetahuan, teknologi, dan seni dalam menyelesaikan permasalahan yang ada pada bidang keilmuan masing-masing. Nama penulis yang artikelnya telah diterbitkan pada suatu jurnal ilmiah dapat menjadi besar (terkenal) karena tulisannya memiliki efek atau pengaruh besar pada suatu keilmuan masing-masing. Hasil analisis metriks sitasi yang dimiliki oleh JAMP: Jurnal Administrasi dan Manajemen Pendidikan seperti yang disajikan pada Tabel 1.

Tabel 1 Metriks Sitasi JAMP: Jurnal Administrasi dan Manajemen Pendidikan

\begin{tabular}{lll}
\hline No & \multicolumn{1}{c}{ Indikator } & \multicolumn{1}{c}{ Jumlah } \\
\hline 1 & Publication years & $2018-2020$ \\
2 & Citation years & 3 \\
3 & Papers & 100 \\
4 & Citations & 388 \\
5 & Cites/year & 129,33 \\
6 & Cites/paper & 3,88 \\
7 & Author/paper & 2,93 \\
8 & h-index & 9 \\
9 & g-index & 16 \\
10 & hI, norm & 6 \\
11 & hI, annual & 2.00 \\
12 & hA, index & 7 \\
\hline & Berdasarkan Tabel 1 & \\
\hline
\end{tabular}

Berdasarkan Tabel 1 dapat diketahui bahwa jumlah artikel yang terbit di JAMP: Jurnal Administrasi dan Manajemen Pendidikan kurun waktu 3 tahun (2018 - 2020) sejumlah 100 artikel, dengan jumlah sitasi sebanyak 388. Rerata jumlah sitasi setiap tahun sebanyak 129,33 sitasi (dari hasil perhitungan seluruh sitasi dibagi 3 tahun). Rerata jumlah sitasi setiap artikel sebanyak 3,88 sitasi (dari hasil perhitungan seluruh sitasi dibagi jumlah artikel). Rerata jumlah penulis artikel yang menulis di jurnal ini sebanyak 2,93. JAMP: Jurnal Administrasi dan Manajemen Pendidikan memiliki h-index sebanyak 9; g-index sebanyak 16; hI norm sebanyak 6; hI annual sebanyak 2.00; dan hA index sebanyak 7.

Jumlah angka sitasi yang diperoleh pada suatu jurnal ilmiah secara keseluruhan juga merupakan salah satu indikator yang digunakan untuk mengevaluasi kualitas jurnal tersebut. Untuk mengetahui kualitas suatu artikel yang diterbitkan di jurnal ilmiah dapat diketahui dari jumlah angka sitasi yang diperoleh dari setiap artikel. Tabel 2 menyajikan daftar 10 artikel dengan jumlah sitasi terbanyak. Artikel dengan sitasi terbanyak adalah artikel dari Maisaro, dkk., (2018), dengan sitasi sebanyak 37. Peringkat 2 artikel dengan banyak sitasi adalah penulis Kusumaningrum, dkk., (2019a), dengan jumlah sitas 34. Dan artikel dengan banyak sitasi yang menduduki peringkat 3 adalah artikel Andiarini \& Nurabadi (2018), dengan jumlah sitasi sebanyak 34. Mengacu pada Tabel 2, nampak bahwa artikel 4 besar dengan sitas terbanyak tidak memiliki selisih jumlah sitasi yang signifikan. Artinya keempat artikel tersebut dapat dikatakan "bersaing ketat" dalam memperoleh sitasi dari artikel lain yang terbit. Peringkat 5 sampai dengan 10 pun juga tidak memiliki selisih angka sitasi yang signifikan. Namun demikian, jika dicermati, 
maka nampak ada gap selisih jumlah sitasi pada kelas 4 besar dengan peringkat 5 ke bawah. Nampaknya ini merupakan indikasi bahwa tema artikel yang menduduki 4 besar dengan sitasi terbanyak memiliki keterkaitan dengan tren penelitian bidang adiministrasi dan manajemen pendidikan pada saat ini.

Tabel 2 Daftar 10 Artikel dengan Jumlah Sitasi Terbanyak pada JAMP: Jurnal Administrasi dan Manajemen Pendidikan

\begin{tabular}{|c|c|c|c|}
\hline No & Jumlah Sitasi & Penulis / Tahun Terbit & Deskripsi Artikel \\
\hline 1 & 37 & Maisaro, dkk., (2018) & $\begin{array}{l}\text { Sebuah studi kualitatif yang mengupas tentang } \\
\text { manajemen program penguatan pendidikan } \\
\text { karakter di sekolah dasar }\end{array}$ \\
\hline 2 & 36 & Kusumaningrum, dkk., (2019a) & $\begin{array}{l}\text { Original artikel yang menyelidiki secara } \\
\text { kuantitatif dampak budaya sekolah terhadap } \\
\text { etika profesi dalam perspektif pemberdayaan } \\
\text { sumber daya manusia sekolah dengan } \\
\text { pendekatan soft system methodology }\end{array}$ \\
\hline 3 & 34 & Andiarini \& Nurabadi (2018) & $\begin{array}{l}\text { Studi kualitatif yang menyelidiki implementasi } \\
\text { program penguatan pendidikan karakter melalui } \\
\text { kegiatan pembiasaan untuk peningkatan mutu } \\
\text { sekolah }\end{array}$ \\
\hline 4 & 32 & Sultoni, dkk., (2018) & $\begin{array}{l}\text { Studi kuantitatif yang bertujuan untuk } \\
\text { mengetahui dampak etika profesional terhadap } \\
\text { pembentukan karakter mahasiswa }\end{array}$ \\
\hline 5 & 20 & Gunawan, dkk., (2018) & $\begin{array}{l}\text { Studi deskriptif tentang pemberdayaan tenaga } \\
\text { administrasi sekolah (TAS) }\end{array}$ \\
\hline 6 & 17 & Sari, dkk., (2018) & $\begin{array}{l}\text { Studi kualitatif yang mengupas pelaksanaan } \\
\text { supervisi manajerial kepala sekolah dalam } \\
\text { rangka implementasi manajemen berbasis } \\
\text { sekolah (MBS) }\end{array}$ \\
\hline 7 & 11 & Bafadal, dkk., (2020b) & $\begin{array}{l}\text { Studi kualitatif dengan content analysis yang } \\
\text { berupaya menentukan tema yang sesuai } \\
\text { pada program debat moral sebagai upaya } \\
\text { meningkatkan integritas kepala sekolah }\end{array}$ \\
\hline 8 & 10 & Sultoni, dkk., (2020) & $\begin{array}{l}\text { Studi kuantitatif yang menyelidiki dampak } \\
\text { pembelajaran berkarakter terhadap penguatan } \\
\text { karakter siswa generasi milenial }\end{array}$ \\
\hline 9 & 10 & Zahro, dkk., (2018) & $\begin{array}{l}\text { Studi kualitatif yang mengulas tentang } \\
\text { kepemimpinan perubahan kepala sekolah }\end{array}$ \\
\hline 10 & 9 & Adipratama, dkk., (2018) & $\begin{array}{l}\text { Studi kualitatif tentang manajemen kurikulum } \\
\text { terpadu di sekolah Islam }\end{array}$ \\
\hline
\end{tabular}

Mengacu pada Tabel 2, dapat diketahui bahwa topik yang menjadi trending di jurnal ini adalah tentang pendidikan karakter (Maisaro, dkk., 2018; Andiarini \& Nurabadi, 2018; Sultoni, dkk., 2018; Sultoni, dkk., 2020); etika (Kusumaningrum, dkk., 2019a; Sultoni, dkk., 2018); budaya sekolah (Kusumaningrum, dkk., 2019a; pemberdayaan sumber daya manusia (Kusumaningrum, dkk., 2019a); supervisi manajerial (Sari, dkk., 2018); integritas kepala sekolah (Bafadal, dkk., 2020b); kepemimpinan perubahan (Zahro, dkk., 2018); manajemen kurikulum (Adipratama, dkk., 2018); dan mutu sekolah (Andiarini \& Nurabadi, 2018). Nampak topik tentang pendidikan karakter dan etika menjadi topik yang hangat di jurnal ini. Topik pendidikan karakter diselidiki oleh 4 artikel, etika dikupas sebanyak 2 artikel, sedangkan topik lainnya hanya 1 artikel. Kesepuluh artikel dalam jurnal ini dapat disebut sebagai artikel yang memiliki pengaruh besar di jurnal. Nampak bahwa jurnal ini memiliki keragaman yang tinggi dari berbagai artikel yang diterbitkan. Keragaman ini muncul juga dipengaruhi oleh penggunaan kata kunci dalam setiap artikelnya. 


\section{PEMBAHASAN}

Mengacu pada terbitan JAMP: Jurnal Administrasi dan Manajemen Pendidikan yang berdurasi empat kali terbit dalam satu tahun (kwartet), nampak jurnal ini memiliki prospek yang menjanjikan, sebab seiring dengan perkembangan dari fokus keilmuan jurnal ini, yang saat ini juga mengalami perkembangan pesat. Sebaran metode yang digunakan di artikel yang diterbitkan pun sangat beragam dan berimbang, sehingga keilmuan administrasi pendidikan yang menjadi fokus jurnal ini dikaji dari berbagai sudut pandang, perspektif, atau suatu frame work (kerangka kerja), sehingga semakin membuat warna dan kaya kajian untuk jurnal ini. Pada 10 besar artikel dengan sitasi terbanyak sebagaimana yang disajikan pada Tabel 2, dapat diketahui komposisi pendekatan penelitian yang digunakan, yaitu 4 dengan metode kuantitatif dan 6 artikel menggunakan metode kualitatif.

Nampak jelas bahwa JAMP: Jurnal Administrasi dan Manajemen Pendidikan memiliki rerata sitasi setiap tahunnya termasuk dalam kategori yang baik. Kutipan atau sitasi memberikan perspektif penelitian baru untuk bibliometric, dapat mengeksplorasi hubungan literatur, dan mekanisme kutipan (Liu, dkk., 2021). Banyak penelitian telah membuktikan bahwa sitasi dapat memberikan informasi penting untuk mendeteksi struktur intelektual (Song, dkk., 2021). Namun, sebagian besar studi ini difokuskan pada penulis pertama. Dalam artikel penelitian, informasi referensi, khususnya konten kutipan atau sitasi, merupakan representasi penting dari komunikasi antar disiplin ilmu yang berbeda (Zhang, dkk., 2021). Menganalisis karakteristik distribusi referensi dari berbagai disiplin ilmu dalam artikel penelitian adalah dasar untuk mendeteksi sumber informasi yang dirujuk dan mengidentifikasi kontribusi dari disiplin ilmu yang berbeda.

Analisis sitasi adalah metode yang umum digunakan untuk memetakan domain pengetahuan dan menggambarkan struktur intelektual ilmiah. Meskipun semua informasi penulis telah dipertimbangkan dalam studi sebelumnya, analisis sitasi tidak membedakan kredit dari kolaborator yang berbeda dalam sebuah tim penulis (Bu, dkk., 2020). Urutan penulis dalam sebuah publikasi menggambarkan kontribusi dan spesialisasi penelitian mereka, yang menawarkan lebih banyak informasi sebagai masukan sebuah analisis sitasi. Meskipun scientometricians telah memfokuskan pada kekuatan dampak kutipan atau sitasi dari publikasi ilmiah, hanya sedikit yang memberi perhatian khusus pada lebar dampak kutipan (Bu, dkk., 2021).

Dari tema yang tren di jurnal ini, nampak bahwa semua tema tersebut merupakan faktor luaran sekolah (school outcomes). Sedangkan faktor input dan proses sebagai kesatuan dalam manajemen sekolah, belum mendapatkan perhatian yang lebih dari para peneliti. Kepemimpinan sebagai faktor utama dari hasil berbagai riset menunjukkan memiliki kontribusi yang positif terhadap capaian siswa (Nurabadi, dkk., 2021; Pambudi \& Gunawan, 2020a; Faizah, dkk., 2020; Setya, dkk., 2020). Kurikulum (Sumarsono, dkk., 2019), kepemimpinan (Gunawan, dkk., 2020a; Bafadal, dkk., 2020a; Prastiawan, dkk., 2020a), pengajaran (Wardani, dkk., 2020b), kinerja guru (Kusumaningrum, dkk., 2020; Shanti, dkk., 2020; Sari, dkk., 2020), strategi pengajaran (Imron, dkk., 2020; Andriningrum, dkk., 2020), e-learning (Siska, dkk., 2020; Gunawan, dkk., 2020b), e-leadership (Nurabadi, dkk., 2020; Ubaidillah, dkk., 2020), iklim sekolah (Prastiawan, dkk., 2020b), dan hubungan masyarakat dengan sekolah (Sumarsono, dkk., 2016), misalnya, bisa menjadi topik yang patut untuk dijadikan bahan oleh para calon penulis jurnal ini. Selain itu, unsur pembiayaan juga sangat menentukan keberhasilan sekolah dalam mencapai visi dan misinya. Nampaknya topik tersebut masih belum banyak dikupas oleh peneliti di jurnal ini.

Mengacu dari teori tentang analisis sitasi, JAMP: Jurnal Administrasi dan Manajemen Pendidikan perlu lebih menekankan lagi pada aspek keragaman sitasi dari artikel yang terkirim di jurnal ini, khususnya pada artikel yang telah direview oleh reviewer dan diambil sebuah keputusan oleh dewan redaksi akan diterima (yang tentu dengan penilaian, misalnya adanya revisi, baik revisi mayor atau pun minor). Selain itu, dewan redaksi juga perlu memperhatikan keragaman kata kunci artikel, sebab keragaman kata kunci (dan tentu harus memperhatikan relevansinya dengan fokus jurnal dan topik riset dari artikel) akan mempengaruhi hasil keyword co-occurrence analysis dan juga bibliometric analysis dari jurnal ini. Kedua analisis itu akan dapat mengetahui relasi dan posisi jurnal ini dengan jurnal lainnya. Semakin kuat total link strength yang dimiliki suatu jurnal, semakin kuat pula posisi dan impact factor jurnal terhadap perkembangan ilmu pengetahuan. 


\section{SIMPULAN}

JAMP: Jurnal Administrasi dan Manajemen Pendidikan merupakan jurnal yang memiliki prospek baik pada masa depan. Hal ini dapat dilihat pada rerata sitasi pertahunnya yang mencapai 129 sitasi. Tema-tema yang cenderung menjadi tren penelitian masa depan pada jurnal ini adalah pendidikan karakter, budaya sekolah, pemberdayaan sumber daya manusia, supervisi manajerial, integritas kepala sekolah, kepemimpinan perubahan, manajemen kurikulum, dan mutu sekolah. Jurnal ini akan mengalami perkembangan dalam hal jumlah sitasi, seiring dengan perkembangan jumlah artikel yang dipublikasikan dan semakin beragamnya topik-topik yang akan muncul pada jurnal ini pada tahun-tahun mendatang.

\section{DAFTAR RUJUKAN}

Adipratama, Z., Sumarsono, R. B., \& Ulfatin, N. (2018). Manajemen kurikulum terpadu di sekolah alam berciri khas Islam. JAMP: Jurnal Administrasi dan Manajemen Pendidikan, 1(3), 372-380.

Aljuaid, H., Iftikhar, R., Ahmad, S., Asif, M., \& Afzal, M. T. (2021). Important citation identification using sentiment analysis of in-text citations. Telematics and Informatics, 56, 1-16.

Andiarini, S. E., \& Nurabadi, A. (2018). Implementasi program penguatan pendidikan karakter melalui kegiatan pembiasaan dalam peningkatan mutu sekolah. JAMP: Jurnal Administrasi dan Manajemen Pendidikan, 1(2), 238-244.

Andriningrum, H., Cholifah, P. S., Gunawan, I., Harisman, A. S. M., Putri, A. F., Amelia, T., ... \& Wulandari, D. A. (2020). Development of Smylings (System for Monitoring Healthy Living Skills) for Health Education in Primary School. In 2020 6th International Conference on Education and Technology (ICET) (pp. 21-25). IEEE.

Bafadal, I., Gunawan, I., \& Nurabadi, A. (2020a). Leadership in Excellent School: A Qualitative Study. In 1st International Conference on Information Technology and Education (ICITE 2020) (pp. 63-66). Atlantis Press.

Bafadal, I., Juharyanto, Nurabadi, A., \& Gunawan, I. (2020b). Debat Moral Sebagai Upaya Meningkatkan Integritas Kepala Sekolah. JAMP: Jurnal Administrasi dan Manajemen Pendidikan, 3(3), 272-282.

Bu, Y., Lu, W., Wu, Y., Chen, H., \& Huang, Y. (2021). How wide is the citation impact of scientific publications? A cross-discipline and large-scale analysis. Information Processing \& Management, 58(1), 1-14.

Bu, Y., Wang, B,. Chinchilla-Rodríguez, Z., Sugimoto, C. R., Huang, Y., \& Huang, W. (2020). Considering author sequence in all-author co-citation analysis. Information Processing \& Management, 57(6), 1-13.

Faizah, A. N., Gunawan, I., Bafadal, I., \& Timan, A. (2020). The Relationship between Learning Leadership and Teacher Performance: A Correlation Analysis. In 1st International Conference on Information Technology and Education (ICITE 2020) (pp. 599-602). Atlantis Press.

Gunawan, I. (2019). Manajemen Kelas Teori dan Aplikasinya. Jakarta: Rajawali Pers.

Gunawan, I., \& Benty, D. D. N. (2017). Manajemen Pendidikan: Suatu Pengantar Praktik. Bandung: Alfabeta.

Gunawan, I., Bafadal, I., \& Nurabadi, A. (2020a). School Leadership Strategy in Excellent Schools. In 6th International Conference on Education and Technology (ICET 2020) (pp. 210-215). Atlantis Press.

Gunawan, I., Hui, L. K., Ma’sum, M. A., \& Sukawati, N. N. (2020b). Enhancing Learning Effectiveness by Using Online Learning Management System. In 2020 6th International Conference on Education and Technology (ICET) (pp. 48-52). IEEE.

Gunawan, I., Triwiyanto, T., Kusumaningrum, D. E. Romady, M., Alfarina, M., \& Widiana, R. A. (2018). Pemberdayaan Tenaga Administrasi Sekolah Menengah Pertama Kota Batu: Studi Deskriptif. JAMP: Jurnal Administrasi dan Manajemen Pendidikan, 1(4), 467-471.

Imron, A., Wiyono, B. B., Hadi, S., Gunawan, I., Abbas, A., Saputra, B. R., \& Perdana, D. B. (2020). Teacher Professional Development to Increase Teacher Commitment in the Era of the Asean Economic Community. In 2nd Early Childhood and Primary Childhood Education (ECPE 2020) (pp. 339-343). Atlantis Press.

Kusumaningrum, D. E., Sumarsono, R. B., \& Gunawan, I. (2019a). Budaya Sekolah dan Etika Profesi: Pengukuran Pemberdayaan Sumber Daya Manusia Sekolah dengan Pendekatan Soft System Methodology. JAMP: Jurnal Administrasi dan Manajemen Pendidikan, 2(3), 90-97.

Kusumaningrum, D. E., Sumarsono, R. B., \& Gunawan, I. (2019b). Professional ethics and teacher teaching performance: Measurement of teacher empowerment with a soft system methodology approach. International Journal of Innovation, Creativity and Change, 5(4), 611-624. 
Kusumaningrum, D. E., Sumarsono, R. B., \& Gunawan, I. (2020). Pendampingan Penulisan Karya Ilmiah Melalui Pendekatan Clinical Coaching bagi Guru Madrasah Inklusi. Abdimas Pedagogi: Jurnal Ilmiah Pengabdian kepada Masyarakat, 3(1), 23-31.

Liu, Y., Yang, L., \& Chen, M. (2021). A new citation concept: Triangular citation in the literature. Journal of Informetrics, 15(2), 1-18.

Maisaro, A., Wiyono, B. B., \& Arifin, I. (2018). Manajemen program penguatan pendidikan karakter di sekolah dasar. JAMP: Jurnal Administrasi dan Manajemen Pendidikan, 1(3), 302-312.

Nurabadi, A., Bafadal, I., Gunawan, I., Burham, A. S. I., \& Bengen, E. J. (2020). Website Development for Principals Induction Program. In 2020 6th International Conference on Education and Technology (ICET) (pp. 205-208). IEEE.

Nurabadi, A., Irianto, J., Bafadal, I., Juharyanto, Gunawan, I., \& Adha, M. A. (2021). The effect of instructional, transformational and spiritual leadership on elementary school teachers'performance and students'achievements. Jurnal Cakrawala Pendidikan, 40(1), 17-31.

Pambudi, B. A., \& Gunawan, I. (2020). The Effect of Learning Leadership, Academic Supervision, and Teacher Skills on Teacher Performance Effectiveness. In 1st International Conference on Information Technology and Education (ICITE 2020) (pp. 1-4). Atlantis Press.

Prastiawan, A., Gunawan, I., Putra, A. P., Dewantoro, D. A., Cholifah, P. S., Nuraini, N. L. S., ... \& Surahman, E. (2020a). School Leadership Skills in Educational Institutions. In 6th International Conference on Education and Technology (ICET 2020) (pp. 438-441). Atlantis Press.

Prastiawan, A., Gunawan, I., Putra, A. P., Dewantoro, D. A., Cholifah, P. S., Nuraini, N. L. S., ... \& Surahman, E. (2020b). Organizational Climate in School Organizations: A Literature Review. In 1st International Conference on Information Technology and Education (ICITE 2020) (pp. 725-728). Atlantis Press.

Sari, D. N. A., Bafadal, I., \& Wiyono, B. B. (2018). Pelaksanaan Supervisi Manajerial dalam Rangka Implementasi Manajemen Berbasis Sekolah. JAMP: Jurnal Administrasi dan Manajemen Pendidikan, 1(2), 213-221.

Sari, D. N., Gunawan, I., \& Imron, A. (2020). Relationship Between Managerial Skills and Morale With Teacher Performance: A Regression Analysis. In 6th International Conference on Education and Technology (ICET 2020) (pp. 125-129). Atlantis Press.

Setya, N. W. N., Gunawan, I., Kusumaningrum, D. E., Sumarsono, R. B., Nurabadi, A., Hui, L. K., ... \& Santoso, F. B. (2020). Development of Student Leadership Variables Instruments: Validity and Reliability Analysis. In 1st International Conference on Information Technology and Education (ICITE 2020) (pp. 541-545). Atlantis Press.

Shanti, C. M., Gunawan, I., \& Sobri, A. Y. (2020). Relationship of School Visionary Leadership and Organizational Climate with Teacher Performance. In 1st International Conference on Information Technology and Education (ICITE 2020) (pp. 624-629). Atlantis Press.

Siska, Rofiah, S. K., Gunawan, I., \& Wardani, A. D. (2020). What Multimedia Can Teachers Use in Learning? In 1st International Conference on Information Technology and Education (ICITE 2020) (pp. 691-695). Atlantis Press.

Song, Y., Wu, L., \& Ma, F. (2021). A study of differences between all-author bibliographic coupling analysis and all-author co-citation analysis in detecting the intellectual structure of a discipline. The Journal of Academic Librarianship, 47(3), 1-9.

Sultoni, Gunawan, I., \& Argadinata, H. (2020). Dampak Pembelajaran Berkarakter Terhadap Penguatan Karakter Siswa Generasi Milenial. JAMP: Jurnal Administrasi dan Manajemen Pendidikan, 3(2), 51-61.

Sultoni, Gunawan, I., \& Sari, D. N. (2018). Pengaruh Etika Profesional Terhadap Pembentukan Karakter Mahasiswa. JAMP: Jurnal Administrasi dan Manajemen Pendidikan, 1(3), 279-283.

Sumarsono, R. B., Imron, A., Wiyono, B. B., \& Arifin, I. (2016). Parents' Participation in Improving the Quality of Elementary School in the City of Malang, East Java, Indonesia. International Education Studies, 9(10), 256-262.

Sumarsono, R. B., Triwiyanto, T., Kusumaningrum, D. E., \& Gunawan, I. (2019). Opportunities for the implementation of school-based management in the eastern area of Indonesia. International Journal of Innovation, Creativity and Change, 5(4), 180-196.

Taftania, S., Kusna, A., Mahardika, B. A., Nugraheni, D. R., Eriyani, D., Yulindasari, N. O., ... \& Gunawan, I. (2020). Implementation of Total Quality Management through the Leadership of Schools in Efforts to Improve Teacher Creativity: A Conceptual Paper. In 1st International Conference on Information Technology and Education (ICITE 2020) (pp. 501-505). Atlantis Press. 
Ubaidillah, E., Gunawan, I., Adha, M. A., Ariyanti, N. S., \& Erviana, Y. (2020). Students Perception of TechnologyAssisted Services and Readiness of Employee Digital Competencies in Covid-19 Pandemic Era. In 6th International Conference on Education and Technology (ICET 2020) (pp. 151-156). Atlantis Press.

Wardani, A. D., Gunawan, I., Kusumaningrum, D. E., Benty, D. D. N., Sumarsono, R. B., Nurabadi, A., ... \& Maulina, S. (2020a). Subject Teacher Deliberation: Role and Functions in School Management. In 1st International Conference on Information Technology and Education (ICITE 2020) (pp. 720-724). Atlantis Press.

Wardani, A. D., Gunawan, I., Kusumaningrum, D. E., Benty, D. D. N., Sumarsono, R. B., Nurabadi, A., ... \& Maulina, S. (2020b). How Teachers Optimize the Role of Classroom Administration in Learning? In 6th International Conference on Education and Technology (ICET 2020) (pp. 422-426). Atlantis Press.

Zahro, A. M., Sobri, A. Y., \& Nurabadi, A. (2018). Kepemimpinan perubahan kepala sekolah dalam peningkatan mutu pendidikan. JAMP: Jurnal Administrasi dan Manajemen Pendidikan, 1(3), 358-363.

Zhang, C., Liu, L., \& Wang, Z. (2021). Characterizing references from different disciplines: A perspective of citation content analysis. Journal of Informetrics, 15(2), 19-30. 